\title{
Inhibition of Penicillium digitatum and Citrus Green Mold by Volatile Compounds Produced by Enterobacter cloacae
}

\author{
Po-Sung Chen ${ }^{1}$, Yu-Hsiang Peng ${ }^{1}$, Wen-Chuan Chung ${ }^{2}$, Kuang-Ren Chung ${ }^{1}$, Hung-Chang Huang ${ }^{3}$ and Jenn-Wen Huang ${ }^{{ }^{*}}$ \\ ${ }^{1}$ Department of Plant Pathology, College of Agriculture and Natural Resources, National Chung-Hsing University, Taichung 40227, Taiwan \\ ${ }^{2}$ Section of Biotechnology, Seed Improvement and Propagation Station, Hsinshe, Taichung 42642, Taiwan \\ ${ }^{3}$ Plant Pathology Division, Agricultural Research Institute, Wufeng, Taichung 41362, Taiwan
}

*Corresponding author: Jenn-Wen Huang, Department of Plant Pathology, National Chung-Hsing University, Taichung, Taiwan, 40227, Tel: 8864228403569; E-mail: jwhuang@dragon.nchu.edu.tw

Received date: March 18, 2016; Accessed date: March 29, 2016; Published date: March 31, 2016

Copyright: (c) 2016 Chen PS, et al. This is an open-access article distributed under the terms of the Creative Commons Attribution License, which permits unrestricted use, distribution, and reproduction in any medium, provided the original author and source are credited.

\begin{abstract}
Penicillium digitatum causes green mold decay on citrus fruit, resulting in severe economic losses to citrus growers and packers worldwide. The present study is to evaluate the control of citrus green mold by volatiles produced by Enterobacter cloacae. An E. cloacae strain isolated from plant rhizospheres was able to produce three volatile organic compounds, which were identified as butyl acetate, phenylethyl alcohol, and 4,5-dimethyl-1-hexene by GC/MS chromatography. The volatile compounds produced by $E$. cloacae inhibited conidial germination and hyphal elongation of $P$. digitatum and reduced green mold severity. $E$. cloacae cultured at temperatures ranging from $16^{\circ} \mathrm{C}$ to $28^{\circ} \mathrm{C}$, at $\mathrm{pH}$ values $\leq 6$, or in a substrate carrier (sphagnum moss, vermiculite, or perlite) provided superior control against $P$. digitatum. A laboratory formulation using $E$. cloacae and perlite protected citrus fruit from green mold up to 22 days and its effectiveness outperformed fungicide application at room temperature $\left(\sim 25^{\circ} \mathrm{C}\right)$. The results implicate practical application of $E$. cloacae as a biofumigant for controlling citrus postharvest decay caused by $P$. digitatum. Significantly, the study provides a model for future research on how to formulate an effective biocontrol agent for disease management.
\end{abstract}

Keywords: Biocontrol; Biofumigant; Fungi; Gas-producing bacterium; Postharvest disease; Orange

\section{Introduction}

Green mold, caused by Penicillium digitatum (Pers.: Fr.) Sacc., is a noxious postharvest disease of citrus. Penicillium digitatum is an opportunistic pathogen that resides on healthy citrus fruit and attacks citrus fruit through injuries caused by rough handling during harvesting, transportation and storage. Infection of $P$. digitatum in citrus often results in tissue maceration and fruit decay. Economic losses caused by green mold decay could be enormous for citrus growers and packers worldwide. Application of fungicides, such as imazalil and thiabendazole, is a common practice to control $P$. digitatum induced fruit decay in the packinghouse [1-4]. However, repeated use of toxic chemical compounds could induce the emergence of fungicide resistant strains of the pathogen and also could increase human health risks.

To lessen the above-mentioned problems, the use of biological control is a promising alternative. Various microorganisms, including Bacillus subtilis, B. pumilus, Burkholderia cepacia, Pseudomonas syringae, $P$. glathei, Pantoea agglomerans, Candida famata, $C$. oleophila, Trichoderma viride, and Myrothecium roridum have been shown to have fungistatic or fungicidal effects to $P$. digitatum and have been explored, with some success, for reducing postharvest green mold decay in citrus [5-15].

Enterobacter cloacae is a rod-shaped, gram-negative bacterium commonly found in plants and has been shown to control a wide range of plant pathogens [16-22] and insect pests [23]. Strains of E. cloacae have been known to produce hydroxamate siderophore, non-volatile metabolites and inorganic volatile substances such as ammonia, all of which might contribute to biocontrol activity [19,24]. Enterobacter cloacae has been shown to inhibit Pythium ultimum sporangium germination and damping-off by competing for fatty acids [25]. Biological control using volatile compounds-producing microorganisms has been reported with increasing success on the various fruit crops and diseases [26-34]. However, little is known about volatile compounds produced by $E$. cloacae. The objectives of this study were to examine whether or not $E$. cloacae will emit volatile compounds and to assess their antimicrobial activity against $P$. digitatum and control of green mold of citrus fruit in storage.

\section{Materials and Methods}

\section{Biological materials and culturing conditions}

The P-51 and DOB-2 strains of $P$. digitatum (Pers. Fr.) Sacc. were single spore isolated from diseased orange fruit grown in Fongyuan and Dalin (Taiwan), respectively. DOB-2 strain has been characterized elsewhere [35]. The affected fruit were incubated in plastic boxes until conidia were produced. Conidia were picked and transferred onto $2 \%$ sucrose water agar. Fungal strains were cultured on potato dextrose agar (PDA; Difco) in a growth chamber with $12 \mathrm{~h}$ daily illumination at $25^{\circ} \mathrm{C}$ to $26^{\circ} \mathrm{C}$. Fungal strains were identified as $P$. digitatum based on the distinct characteristics of conidia and colony morphologies formed on malt extract agar (MEA), Czapek yeast autolysate agar (CYA), and glycerol nitrate agar (GN25N) as described by Pitt [36]. The identity of $P$. digitatum was further confirmed by sequence analysis of the $5.8 \mathrm{~S}$ ribosomal internal transcribed spacers (ITS). 
Bacterial strains were single-colony isolated from rhizospheres of Yardlong bean (Vigna sesquipedalis (L.) Fruwith). Bacterial cells were grown on King's medium $\mathrm{B}(\mathrm{KB})$ plate at $30^{\circ} \mathrm{C}$ for 2 days, harvested by low speed centrifugation (4000× rpm), suspended in $20 \%$ glycerol water, and stored at $-80^{\circ} \mathrm{C}$. Bacterial strains were identified as $E$. cloacae by sequence analysis of an $r p o B$ gene encoding a RNA polymerase $\beta$-subunit.

\section{Identification of and fungal bacterial strains}

Microbial genomic DNA was extracted with phenol/chloroform partition and precipitated with isopropanol. Fungal 5.8S rDNA was amplified by PCR with the primers ITS1 (5'TCCGTAGGTGAACCTGCGG-3') and ITS4 (5'TCCTCCGCTTATTGATATGC-3') as described by White and colleagues [37]. Bacterial DNA fragment was amplified with colony PCR as described by Fukui and Sawabe [38] using a PCR Master Mix kit (GeneMark, Taichung, Taiwan). Bacterial $r p o B$ gene was amplified by PCR with the primers CM7 (5'AACCAGTTCCGCGTTGGCCTGG-3') and CM31b (5'CCTGAACAACACGCTCGGA-3') as described by Mollet and colleagues [39]. PCR fragments were directly sequenced. Sequences were searched against the databases at the National Center for Biotechnology Information (NCBI) using the BLAST network service to determine the similarity of the amplified fragments. Sequence data reported in this article have been deposited in the EMBL/GenBank Data Libraries under accession numbers AJ543728 (E006 rpoB) and AJ543682 (E010 rpoB)

\section{Volatile antimicrobial assays}

In-vitro volatile antimicrobial activity was assessed using a plate-toplate method as described $[27,40]$. Bacterial cells grown on KB agar at $24^{\circ} \mathrm{C}$ for $24 \mathrm{~h}$ were used for antifungal activity assays. Petri dish lips were removed and the plate was turned upside down and attached onto a coverless PDA plate containing conidia or an agar plug bearing 2day-old mycelium of $P$. digitatum. The gap between plates was tightly sealed with two layers of parafilm (American National Can, Chicago, USA) and the plates incubated at varying temperatures. Spore germination was determined microscopically $24 \mathrm{~h}$ after treatment. Radial growth of fungus was measured at 7 days after treatment. A KB agar plate without $E$. cloacae and a PDA plate with $P$. digitatum were used as mock controls. Fungal viability was assessed after treatments by transferring agar plugs covering with $P$. digitatum mycelium onto freshly prepared PDA. Percentage of growth inhibition of $P$. digitatum was determined by dividing the relative difference of the growth between mock control and treatment by the control growth and then multiplying by 100 . Percentage of inhibition $=[(\mathrm{A}-\mathrm{B}) / \mathrm{A}] \times 100$, where A is the average diameter of $P$. digitatum without being challenged with E. cloacae (mock control); B is the average diameter of $P$. digitatum grown in the presence of $E$. cloacae. Effect of volatile compounds on spore germination was also assessed using $P$. digitatum conidia. Unless otherwise stated, all experiments were repeated at least twice with three replicates.

\section{$S P M E / G C-M S$ identification of volatile compounds}

Enterobacter cloacae strain was grown on $\mathrm{KB}$ plate or in perlite mixed with $\mathrm{KB}$ broth at $30^{\circ} \mathrm{C}$ for 2 days. Volatile compounds were extracted by a headspace solid-phase microextraction (HS-SPME) device (SUPELCO, Bellefonte, PA, USA) equipped with 50/30 $\mu \mathrm{m}$ Divinylbenzene/Carboxen/Polydimethylsiloxane (DVB/CAR/PDMS,
SUPELCO) fibers. After $15 \mathrm{~min}$, the HS-SPME device was removed and inserted into the injector $\left(200^{\circ} \mathrm{C}\right)$ of a gas chromatograph (GC)mass spectrophotometer (MS) equipped with a Model CP-3800 GC and a Saturn 2000 MS (Varian, USA) connecting to an electron capture detector (Model 902B, ECD, splitless mode). Nitrogen was used as a gas carrier and flowed at $0.2 \mathrm{~mL} / \mathrm{min}$ through a VF-5MS capillary column $(30.0 \mathrm{~m} \times 0.25 \mathrm{~mm}$ ID, $0.25 \mu \mathrm{m}$ film thickness, Agilent, Santa Clara, CA, USA). Analytical temperatures modified from Kai et al., [41] were set as following: Initial column temperature at $40^{\circ} \mathrm{C}$ for 2 min, followed by a ramp of $5^{\circ} \mathrm{C} / \mathrm{min}$ up to $170^{\circ} \mathrm{C}$ with a final hold for 1 min at $170^{\circ} \mathrm{C}$. $\mathrm{KB}$ medium without bacteria was used as controls. The identities of volatile compounds were verified by comparing them with chemical databases deposited in the GC-mass spectra (GC-MS) library (Saturn 2000, USA). Phenylethyl alcohol (PEA) and butyl acetate (BA) were purchased from Sigma-Aldrich (St. Luis, MO, USA). The toxicity of commercially available chemicals individually or in combination on the growth of $P$. digitatum also was assessed by modified plate-to-plate assays by placing a test compound onto a filter paper disc $(0.5 \mathrm{~cm}$ in diameter).

\section{Fungal inoculation and assays for disease severity}

Fruit of 'Gold Seal' orange (Citrus sinensis Osbeck), showing no visible lesions or injuries, were collected from an orchard in Gukeng (Yunlin county, Taiwan) and used throughout the experiment. Citrus fruit stored at $11^{\circ} \mathrm{C}$ for 5 to 7 days were washed by immersing in distilled water, surface sterilized with $70 \%$ alcohol, and dried in a sterile hood. Conidia of $P$. digitatum were harvested by flooding with sterile water containing $0.01 \%$ Tween 20 and the concentration was adjusted to $10^{4}$ conidia per milliliter with the use of a haemocytometer. Orange fruit were wounded with $2 \mathrm{~mm}$ long by $1 \mathrm{~mm}$ wide tips (10) mounted on a steel rode as described [30] prior to inoculation. The wounded fruit were immersed in conidial suspensions or water for 10 s, dried, and placed in plastic boxes (Lock\&Lock, HanaCobi, Korea) for lesion development with or without $E$. cloacae $\left(1.2-1.8 \times 10^{8}\right.$ $\mathrm{cfu} / \mathrm{mL}$ ) mixed in sterilized substrates. Fruit were soaked in a benomyl (200 ppm) or thiabendazole (2000 ppm; Mertect 41.8\% SC; Sinon, Taiwan) solution for $30 \mathrm{~min}$ prior to inoculation as controls. Commercially available substrates: sphagnum moss (YuGuang Garden, Taichung, Taiwan), vermiculite (NanHai Co., New Taipei City, Taiwan), peat moss (BVB no. 4, Bas Van Buuren, Maasland, New Zealand) and perlite (NanHai) were sterilized and added to different concentrations of KB. A 5-fold $\mathrm{KB}$ stock (each liter contains $15 \mathrm{~g}$ peptone, $1.125 \mathrm{~g} \mathrm{~K}_{2} \mathrm{HPO}_{4}, 1.125 \mathrm{~g} \mathrm{MgSO}_{4}$. $7 \mathrm{H}_{2} \mathrm{O}$, and $7.5 \mathrm{ml}$ glycerol) was prepared, diluted, and mixed with substrates. Disease severity was rated in each fruit according to the following scale: $0=$ No symptoms; $1=$ Less than $25 \%$ of fruit surface showing symptoms; $2=26$ to $50 \%$ of fruit surface showing symptoms; $3=$ More than $50 \%$ of fruit surface showing. Percentage of disease severity was calculated from the disease rating by the formula:

$$
\text { Disease Severity }(\%)=\frac{\left.\sum \text { (Rating no. } \times \text { the no. of fruits }\right)}{\text { Total no. of fruits } \times 3} \times 100
$$

The experiment was performed three times; each replicate contained 10 fruit. The significance of treatments was determined by analysis of variance (ANOVA) and treatment means separated by nonlinear regression and Durbin-Watson Statistic normality tests using SigmaPlot 10 (Systat Software, San Jose, CA). 
Citation: Chen PS, Peng YH, Chung WC, Chung KR, Huang HC, et al. (2016) Inhibition of Penicillium digitatum and Citrus Green Mold by Volatile Compounds Produced by Enterobacter cloacae. J Plant Pathol Microbiol 7: 339. doi:10.4172/2157-7471.1000339

Page 3 of 8

\section{Result}

\section{Fungistatic effects of volatile compounds produced by $E$. cloacae}

Pathogenicity assays revealed that both fungal strains were highly pathogenic to citrus (data not shown). Using plate-to-plate assays, we screened over 200 bacterial isolates and found that E. cloacae isolate E010 displayed inhibitory effects on vegetative growth and conidial germination of both $P$. digitatum P51 and DOB-2 strains (Table 1 and data not shown). Because $E$. cloacae and $P$. digitatum were cultured on different agar plates and never physically contacted each other, the inhibitory effects observed in $P$. digitatum were likely attributable to the production of volatile compounds that were toxic to fungus. Volatile compounds produced by the E006 strain had less effect on fungal growth and conidial germination compared to those produced by the E010 strain. Although volatile compounds produced by the E006 strain effectively suppressed the germination of conidia produced by $P$. digitatum $\mathrm{P} 51$ isolate, the compounds had little effect on conidial germination of DOB-2 isolate. Thus, E010 strain was chosen for further analyses. Exposure of $P$. digitatum to E. cloacae resulted in abnormal growth of fungal colony, producing more aerial hyphae. The effect of volatile compounds to $P$. digitatum was fungistatic as hyphae resumed normal growth after transferring onto freshly prepared PDA (data not shown).

\begin{tabular}{|l|l|l|}
\hline \multirow{2}{*}{ Bacterial strain } & \multicolumn{2}{|l|}{$\%$ of inhibition $^{2}$} \\
\cline { 2 - 3 } & P51 & DOB-2 \\
\hline E006 & $97.6 \pm 0.9 \mathrm{a}$ & $30.2 \pm 8.4 \mathrm{~b}$ \\
\hline Conidial germination & $15.3 \pm 9.0 \mathrm{~b}$ & $27.8 \pm 2.8 \mathrm{~b}$ \\
\hline Radial growth & \multicolumn{2}{|l}{} \\
\hline E010 & $97.0 \pm 1.0 \mathrm{a}$ & $87.9 \pm 2.3 \mathrm{a}$ \\
\hline Conidial germination & $100 \pm 0.0 \mathrm{a}$ & $89.8 \pm 0.3 \mathrm{a}$ \\
\hline Radial growth &
\end{tabular}

Table 1: Inhibition of conidial germination and radial growth of Penicillium digitatum by Enterobacter cloacae using plate-to-plate assays $^{1}$.

- $\quad{ }^{1}$ E. cloacae strains E006 and E010 were cultured on King's medium B and $P$. digitatum isolates P51 and DOB-2 were cultured on PDA at 24 for $24 \mathrm{~h}$. Petri dish plates were attached and incubated for an additional $24 \mathrm{~h}$. Experiments were repeated three times with at least 3 replicates for each treatment.

- ${ }^{2}$ Means in the same column followed by the same letter are not significantly different according to nonlinear regression and Durbin-Watson Statistic normality tests $(\mathrm{P}=0.05)$.

\section{Effect of environmental conditions used to grow $E$. cloacae on antifungal activity}

To assess if temperature would affect $E$. cloacae's ability to inhibit conidial germination, E010 strain was grown at temperatures varying between 16 and $32^{\circ} \mathrm{C}$ for $24 \mathrm{~h}$. Conidia prepared from P. digitatum P51 and DOB-2 isolates were placed on PDA and the plates were attached onto the E010 plates using plate-to-plate assays and incubated at respective temperatures. In the absence of bacterial culture, the efficacy of conidial germination measured in both P51 and DOB-2 isolates increased exponentially at temperatures between 16 and $24^{\circ} \mathrm{C}$ and decreased sharply at temperatures greater than $28^{\circ} \mathrm{C}$ (Figure $1 \mathrm{~A}$ ). Penicillium digitatum conidia failed to germinate efficiently while grown at $32^{\circ} \mathrm{C}$. The rate and magnitude of conidial germination reduced considerably when the agar plate carrying E010 strain was attached to the plates culturing fungal strains. In general, conidia of both $P$. digitatum strains germinated poorly when co-cultured with E010 bacterium grown at temperatures greater than $20^{\circ} \mathrm{C}$. The $\mathrm{pH}$ values of medium used to culture $E$. cloacae also affected its efficacy of antifungal activity. E010 strain grown at acidic $\mathrm{pH} \leq 6$ displayed a strong inhibition on conidial germination of $P$. digitatum (Figure 1B). The inhibitory effect on conidial germination decreased markedly when E010 was cultured on medium with $\mathrm{pH}$ values greater than 6 .
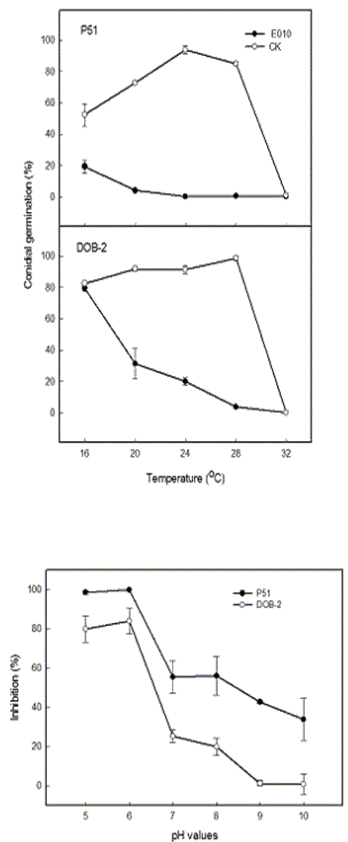

Figure 1: Effect of environmental conditions on the ability of Enterobacter cloacae to inhibit the germination of conidia produced by Penicillium digitatum strains assessed using plate-to-plate assays. (A) Effect of temperature on E. cloacae's ability to inhibit the germination of conidia produced by P51 and DOB-2 strains. (B) Effect of the $\mathrm{pH}$ valves on $E$. cloacae's ability to inhibit the germination of conidia produced by $\mathrm{P} 51$ and DOB-2 strains. The $E$. cloacae $\mathrm{E} 010$ strain was cultured on $\mathrm{KB}$ medium at varying temperatures for $24 \mathrm{~h}$. The KB medium plates were attached to PDA plates culturing $\mathrm{P} 51$ or DOB-2 and incubated for an additional 24 $\mathrm{h}$. The percentage of conidial germination was compared to those attached to KB medium plates only.

\section{Control of citrus green mold by $\boldsymbol{E}$. cloacae}

Experiment was undertaken to evaluate if $E$. cloacae would be useful for controlling citrus green mold caused by $P$. digitatum and if substrates used to culture bacterium would impact $E$. cloacae's ability to inhibit test fungi. Increasing the amounts of fungal inoculum greatly increased the severity of green mold on citrus (Figure 2A). 
Citation: Chen PS, Peng YH, Chung WC, Chung KR, Huang HC, et al. (2016) Inhibition of Penicillium digitatum and Citrus Green Mold by Volatile Compounds Produced by Enterobacter cloacae. J Plant Pathol Microbiol 7: 339. doi:10.4172/2157-7471.1000339

Page 4 of 8

Enterobacter cloacae and conidia suspended in $\mathrm{KB}$ or $\mathrm{H}_{2} \mathrm{O}$ were mixed with sphagnum moss, vermiculite, peat moss, or perlite and incubated in a plastic box with test citrus fruit (Figure 2B). The results revealed that the substrates used to support the growth of E. cloacae had a profound impact on the effectiveness of reducing green mold. Fruit inoculated with $P$. digitatum developed green mold at 7 days post inoculation (dpi) in all treatments without exogenous application of $E$. cloacae (Table 2).

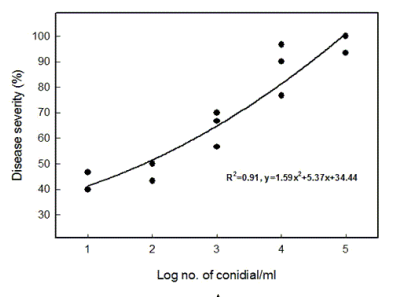

A

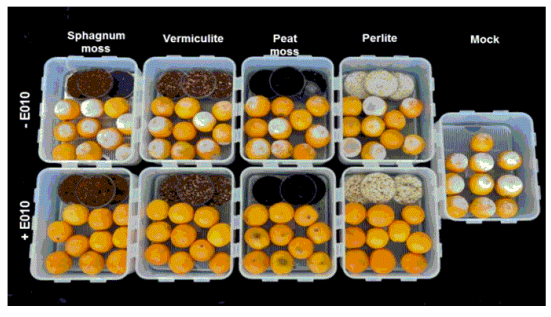

B

Figure 2: Citrus green mold produced by Penicillium digitatum. (A) Severity of citrus green mold was correlated with the amounts of inoculum prepared from conidia of $P$. digitatum strain E010. (B) Development of green mold on citrus fruit inoculated with conidial suspension of $P$. digitatum in the presence of Enterobacter cloacae E010 strain cultured in KB medium mixed with different substrates (3 plates) incubated at room temperature for 7 days. Experiments were repeated three times with 10 fruit for each treatment. Only representatives are shown.

\begin{tabular}{|c|c|c|}
\hline \multirow{2}{*}{ Substrate } & \multicolumn{2}{|c|}{ Disease severity (\%) } \\
\cline { 2 - 3 } & + E010 & - E010 \\
\hline Peat moss & $65.6 \pm 8.7 \mathrm{~b}$ & $91.1 \pm 5.6 \mathrm{a}$ \\
\hline Perlite & $0 \mathrm{c}$ & $80.0 \pm 5.1 \mathrm{~b}$ \\
\hline Sphagnum moss & $0 \mathrm{c}$ & $90.0 \pm 3.3 \mathrm{ab}$ \\
\hline Vermiculite $^{4}$ & $0 \mathrm{c}$ & $95.6 \pm 1.1 \mathrm{a}$ \\
\hline Medium control $^{2}$ & $95.6 \pm 4.4 \mathrm{a}$ & $96.7 \pm 3.3 \mathrm{a}$ \\
\hline $\mathrm{H}_{2} \mathrm{O}$ control $^{3}$ & $98.9 \pm 1.1 \mathrm{a}$ & $100.0 \pm 0.0 \mathrm{a}$ \\
\hline
\end{tabular}

Table 2: Reduction of citrus green mold caused by Penicillium digitatum by Enterobacter cloacae grown in King's medium B and different substrates ${ }^{1}$.

- $\quad{ }^{1}$ E. cloacae strain E010 was cultured in King's medium B (KB, 75 $\mathrm{ml})$ mixed with different substrate $(150 \mathrm{ml})$ in a moist chamber along with citrus fruit inoculated with $P$. digitatum for 7 days at room temperature.
- $\quad{ }^{2}$ Medium control contained medium ingredients without adding substrates.

- ${ }^{3} \mathrm{H}_{2} \mathrm{O}$ control $\left(75 \mathrm{ml}\right.$ distilled $\mathrm{H}_{2} \mathrm{O}$ ) contained no substrate and medium ingredients.

- ${ }^{4}$ Means $(n=10)$ in the same column followed by the same letter are not significantly different according to nonlinear regression and Durbin-Watson Statistic normality tests $(\mathrm{P}=0.05)$.

Notably, in the absence of $E$. cloacae, fruit incubated with perlite alone reduced green mold severity by $20 \%$ compared with other treatments. Enterobacter cloacae cultured in peat moss provided moderate protection from green mold. None of citrus fruit developed green mold symptoms when incubating with E. cloacae cultured in sphagnum moss, vermiculite, or perlite. Enterobacter cloacae cultured in $\mathrm{KB}$ or water (mock controls) failed to reduce green mold severity.

In order to optimize E. cloacae-substrate formulation for controlling citrus green mold, we further tested the effectiveness of a combined E010-KB-perlite (EKP) formula on the occurrence of the disease. Green mold severity decreased significantly as the volume of EKP increased (Figure 3A). Decreasing the ingredient concentrations in $\mathrm{KB}$ medium and then, mixing with perlite and E010 decreased the green mold severity substantially (Figure 3B).
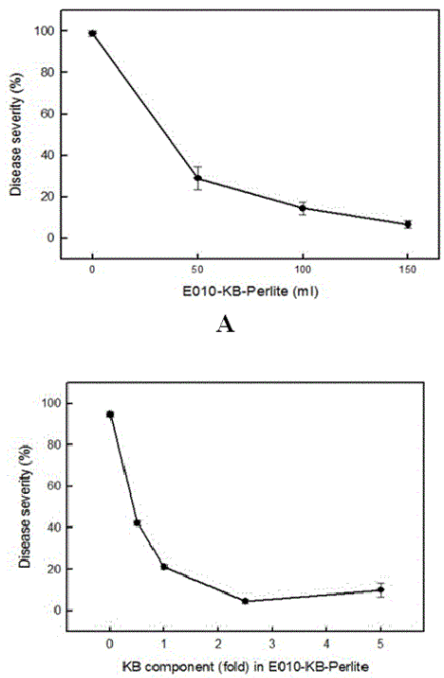

B

Figure 3: Reduction of citrus green mold severity by E010-KBperlite formulation. (A) Enterobacter cloacae E010 cultured in KB and perlite (E010-KB-perlite) was prepared in different amounts and placed in a moist chamber along with citrus fruit inoculated with $P$. digitatum $\mathrm{P} 51$ and incubated at room temperature for 7 days. (B) Reduction of green mold severity caused by $P$. digitatum due to the increase of $\mathrm{KB}$ concentrations in the E010-KB-perlite formulation. Experiments were repeated twice with 10 fruit for each treatment.

Using 5-fold $\mathrm{KB}$ in $\mathrm{EKP}\left(\mathrm{EK}_{5} \mathrm{P}\right)$ citrus fruit were protected from green mold up to 22 days at room temperature $\left(\sim 25^{\circ} \mathrm{C}\right)$ (Figure $4 \mathrm{~A}$ ); whereas EKP with 2.5 -fold $\mathrm{KB}$ ingredients $\left(\mathrm{EK}_{2.5} \mathrm{P}\right)$ provided less protection over time (Figure $4 \mathrm{~B}$ ). Further studies revealed that $\mathrm{EK}_{5} \mathrm{P}$ reduced green mold incidence in a wide range of test temperatures (from 8 to $20^{\circ} \mathrm{C}$ ) (Figure $4 \mathrm{C}$ ). Uninoculated fruit never developed 
Citation: Chen PS, Peng YH, Chung WC, Chung KR, Huang HC, et al. (2016) Inhibition of Penicillium digitatum and Citrus Green Mold by Volatile Compounds Produced by Enterobacter cloacae. J Plant Pathol Microbiol 7: 339. doi:10.4172/2157-7471.1000339

Page 5 of 8

green mold symptoms during the course of the experiment (data not shown). Citrus fruit soaked in benomyl (200 ppm), thiabendazole (2000 ppm), or water prior to inoculation failed to provide any protection from $P$. digitatum, whereas application of $\mathrm{EK}_{5} \mathrm{P}$ reduced green mold development substantially (Figure 4D).
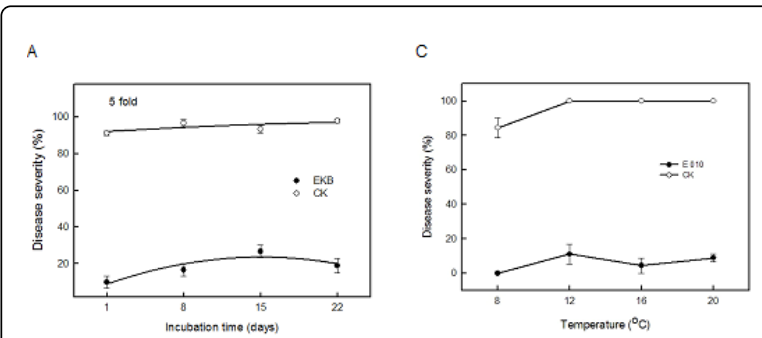

B

D
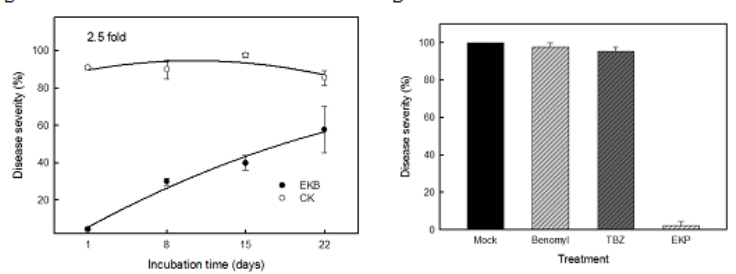

Figure 4: Control of citrus green mold by Enterobacter cloacae E010 cultured in $\mathrm{KB}$ and perlite. (A) Using 5 -fold $\mathrm{KB}$ medium in the E010-KB-perlite $\left(\mathrm{EK}_{5} \mathrm{P}\right)$ formulation, citrus fruit were protected from green mold caused by $P$. digitatum up to 22 days at room temperature. (B) Using 2.5-fold $\mathrm{KB}$ medium in the E010-KB-perlite formulation provided moderate protection against $P$. digitatum. (C) Using E010-KB-perlite $\left(\mathrm{EK}_{5} \mathrm{P}\right)$ formulation citrus fruit were protected from green mold at temperatures ranging from 8 to $20^{\circ} \mathrm{C}$. (D) E010-KB-perlite $\left(\mathrm{EK}_{5} \mathrm{P}\right)$ had superior effect on the reduction of citrus green mold compared to fungicides benomyl (at $200 \mathrm{ppm}$ ) and thiabendazole (TBZ at $2000 \mathrm{ppm}$ ). Mock control (CK) was treated with water only. Each treatment contained 10 fruit.

\section{GC/MS identification of volatile compounds produced by $E$. cloacae}

Volatile compounds produced by $E$. cloacae grown on KB medium were identified after gas trapping and GC/MS separation (Figure 5). Compounds commonly identified from the gas phase of both the control and the E. cloacae-growing culture were eliminated. The volatile substances 4,5-dimethyl-1-hexene and phenylethyl alcohol uniquely found in the bacterium-grown medium were identified by comparing them in the GC-mass spectra (GC-MS) database library. Apart from these two compounds, butyl acetate was identified from gas phase of $E$. cloacae grown on $\mathrm{KB}$ medium mixed with perlite (Figure 5). The identity of phenylethyl alcohol and butyl acetate was further verified by comparison with authentic standards that were commercially available. Although 4,5-dimethyl-1-hexene is commercially available, we were unable to obtain this compound due to a shipping restriction of the product.

\section{Suppression of $\boldsymbol{P}$. digitatum and citrus green mold by volatile compounds}

Co-incubation of $P$. digitatum P51 or DOB-2 isolate with commercially available butyl acetate or phenylethyl alcohol alone at test concentrations had little or no effect on conidial germination (data not shown) and radial growth (Figure 6).
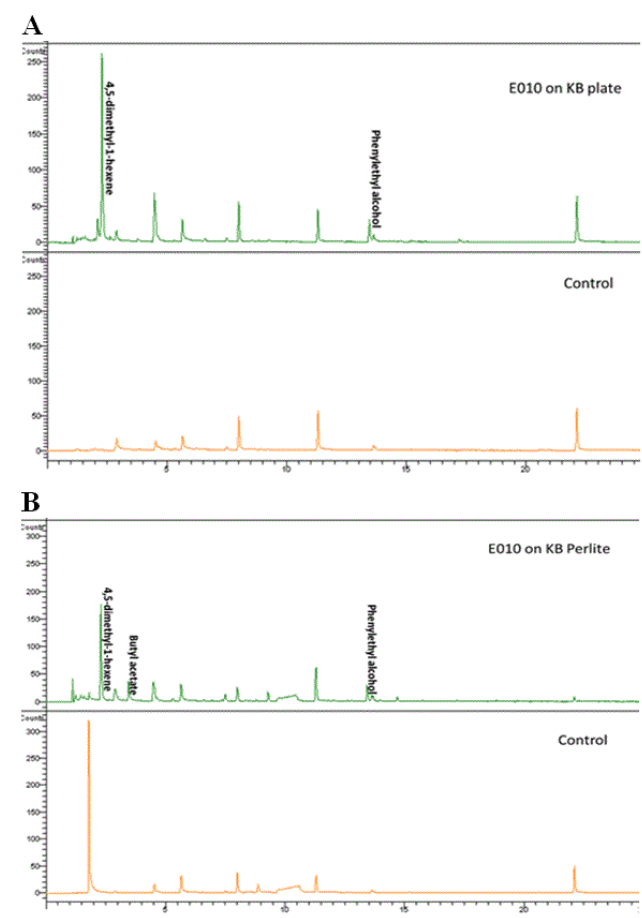

Figure 5: SPME/GC-MS chromatogram. GC/MS chromatogram of volatile compounds identified from gas phase of Enterobacter cloacae E010 cultured in (A) KB or (B) KB mixed with perlite (KBperlite). Mock control (CK) contained KB medium only. E010 strain was grown in $\mathrm{KB}$ broth at $30^{\circ} \mathrm{C}$ for 2 days. Volatile compounds were collected using a solid-phase microextraction (SPME) device and analyzed by GC/MS chromatography.

A combination of butyl acetate and phenylethyl alcohol had a moderate effect on the suppression of conidial germination prepared from $P$. digitatum P51 strain, but inhibited the germination by nearly $40 \%$ of conidia prepared from $P$. digitatum DOB-2 strain. Mixture of butyl acetate and phenylethyl alcohol suppressed radial growth of both P51 and DOB-2 strains (Figure 6). When tested for green mold control, application of phenylethyl alcohol alone did not provide apparent protection against citrus green mold; however, application of butyl acetate alone or in combination with phenylethyl alcohol provided low levels of protection of citrus fruit from green mold (Figure 7). Notably, butyl acetate and phenylethyl alcohol had no synergistic effects in the context of disease reduction. Lack of commercially available 4,5-dimethyl-1-hexene prevented us from testing its toxicity toward $P$. digitatum.

\section{Discussion}

In Taiwan, benzimidazole is the primary fungicide recommended to control postharvest citrus diseases and more than $97 \%$ of $P$. digitatum isolates were found to be resistant to this fungicide [35]. In the present study, we identified an E010 bacterium collected from rhizospheres of Yardlong bean as $E$. cloacae based on sequence analysis of an $r p o B$ gene and have demonstrated its ability of producing antimicrobial 
volatile compounds, as well as its potential use as a biocontrol agent for controlling citrus green mold.

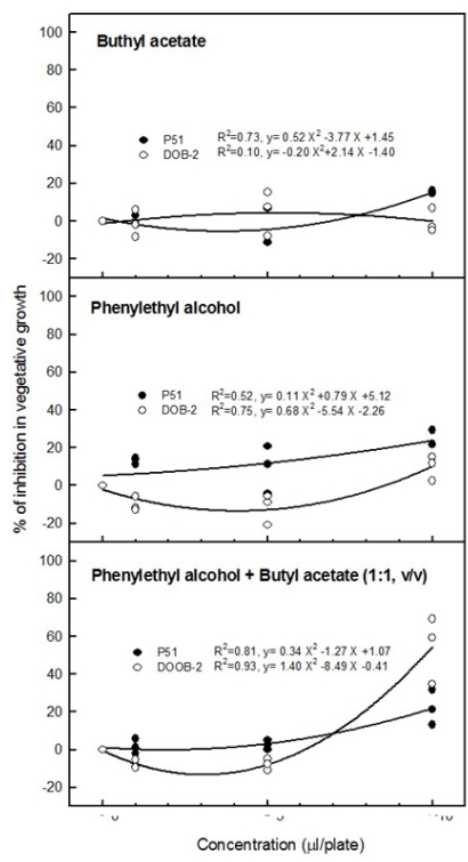

Figure 6: Effects of commercially available compounds: butyl acetate (BA) and phenylethyl alcohol (PEA) individually or in combination on vegetative growth of $P$. digitatum strains (P51 and DOB-2). Fungal strains were placed on PDA and the plates were attached to petri dish plates containing a filter paper disc with a test compound. Experiments were repeated three times with 3 replicates for each treatment. Only representatives are shown.

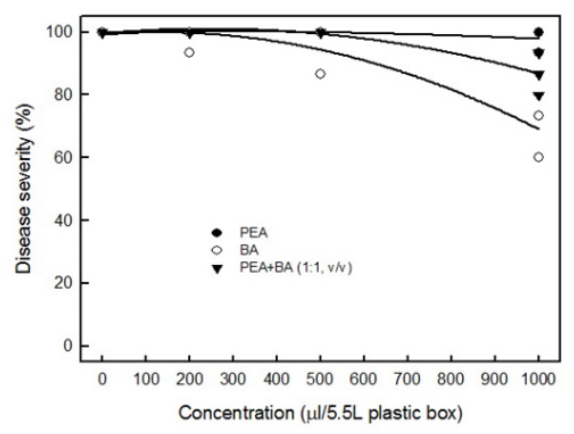

Figure 7: Effects of commercially available compounds: butyl acetate (BA) and phenylethyl alcohol (PEA) individually or in combination, on the reduction of citrus green mold caused by $P$. digitatum. Filter paper discs spotted with various with chemicals were placed in a petri dish along with citrus fruit inoculated with conidial suspension of the $P$. digitatum P51 strain and incubated in a moist box for 7 days at room temperature.

The chemical properties and the biological activities of volatile compounds produced by $E$. cloacae were characterized to be inhibitory to fungal pathogen $P$. digitatum causing citrus green mold. The environmental conditions that might influence the production of volatile compounds by $E$. cloacae and its effectiveness of controlling green mold were also investigated. Temperatures and substrates used to culture $E$. cloacae and $\mathrm{pH}$ values of medium all affected $P$. digitatum-induced disease severity on citrus fruit. The efficacy of a well-known volatile antimicrobial producer Muscodor albus as a biofumigant also is affected by temperatures $[42,43]$. Nevertheless, our results provide valuable information in determining the importance and practicability of utilizing $E$. cloacae as a biocontrol means in controlling citrus green mold.

Using plate-to-plate assays, it was noticed that $E$. cloacae grown at temperatures ranging from $16^{\circ} \mathrm{C}$ to $28^{\circ} \mathrm{C}$ was able to suppress the germination of conidia produced by $P$. digitatum. Green mold incidence on citrus stored at temperatures ranging from $8^{\circ} \mathrm{C}$ to $20^{\circ} \mathrm{C}$ also was suppressed using E010-KB-Perlite (EKP) formulation. Enterobacter cloacae grown in acidic $\mathrm{pH}$ tended to exhibit stronger toxicity toward $P$. digitatum than that grown in alkaline conditions. This could be related to bacterial growth as E. cloacae grew much better in acidic environments [44]. We found that the composition of the medium can impact the bacterial growth and the type of volatile compounds produced by $E$. cloacae. In the end, a combination by growing E. cloacae E010 strain in 5-fold $\mathrm{KB}$ medium and perlite $\left(\mathrm{EK}_{5} \mathrm{P}\right)$ was found to be the most effective formula for controlling green mold. $\mathrm{EK}_{5} \mathrm{P}$ seems to provide much protection against green mold, keeping citrus fruit from the disease up to 3 weeks. Perlite is a volcanic stone comprising silicon dioxide, ammonium oxide, and many other minerals, and has been widely used in the industry and agriculture sectors. Owing to its high permeability and low water retention, perlite is often used as a soil amendment and as a carrier for fertilizers, herbicides and pesticides [45].

Enterobacter cloacae is not a prolific producer of volatile compounds. Only an isolate of $E$. cloacae has been reported to emit ammonium [19]. Although only three volatile compounds were identified from analysis of gas phase of $E$. cloacae in this study, the bacterium demonstrates its impressive biological activity against $P$. digitatum and citrus green mold. It is very likely that changing the composition of growth medium may increase the number and the type of volatile compounds produced by $E$. cloacae as suggested in gasproducing fungus Muscodor albus [28]. Moreover, a combination of three volatile compounds (4,5-dimethyl-1-hexene, butyl acetate and phenylethyl alcohol) is likely required to exert a stronger inhibitory effect against the target test $P$. digitatum. Phenylethyl alcohol is a common gas released by bacteria and fungi and exerts antimicrobial activities against various plant pathogenic fungi at very high levels or in cooperation with other volatile compounds [33,40,41,46-48]. Phenylethyl alcohol has rose-like flavors and has been demonstrated to induce germination of ascospores, but suppress conidial germination in Neurospora crassa [49,50]. Phenylethyl alcohol affects membrane permeability, causes the alternation of amino acid and sugar transport systems, and inhibits the synthesis of macromoleculars and thus, is inhibitory to microorganisms [51,52]. Like trytophol, phenylethyl alcohol is involved in fungal quorum sensing [53]. Butyl acetate, also known butyl ethanoate, has sweet smell of banana or apple and can be inhibitory to bacteria [54].

Although artificial application of volatile compounds did not fully suppress fungal growth and conidial germination, they mimicked the inhibitory effects to some extent. The differences in activity between the E. cloacae-involved production of volatiles and commercially 
available products may relate to the quantitative production of the volatile compounds produced by E010, which cannot be determined by our GC/MS methodology. Another explanation for less inhibitory effect of commercially available products on $P$. digitatum is that volatile compounds exert their maximal toxicity in a cooperative manner. Exogenous application of butyl acetate or phenylethyl alcohol individually had little effect on conidial germination and radial growth of $P$. digitatum, whereas a combination of both compounds inhibits conidial germination and vegetative growth. The results confirm the synergistic effect of volatile compounds in terms of their toxicity toward $P$. digitatum. Similar synergism among volatile organic compounds in increasing antimicrobial activity has also been observed $[28,55]$. The toxicity of 4,5 -dimethyl-1-hexene alone to $P$. digitatum remains uncertain. However, of three volatile compounds identified from gas phase of $E$. cloacae, 4,5-dimethyl-1-hexene is the predominant compound. Judging from differences in activity between the E. cloacae-producing volatile compounds and commercially available butyl acetate and phenylethyl alcohol, it appears that 4,5dimethyl-1-hexene plays an important role in fungistatic effects against $P$. digitatum, as well as in suppressing green mold incidence. Evaluation of the toxicity of 4,5-dimethyl-1-hexene will be the next logical step toward better understanding of how E. cloacae exerts its antimicrobial ability.

Delayed application of EKP could be ineffective in controlling green mold, since volatile compounds emitted by $E$. cloacae only inhibit but do not kill $P$. digitatum. Further experiments to determine the optimal growth condition for $E$. cloacae that provides the most effective measure in controlling citrus green mold in a closed chamber during storage and shipment are warranted. It will also be of interest to determine if volatile compounds produced by $E$. cloacae can be inhibitory to other plant pathogenic fungi and if EKP formula is useful in controlling other plant diseases. The study also paves a way for future research on how to formulate an effective biocontrol agent for disease management.

\section{Acknowlegement}

This research was supported by a grant from the National Science and Technology Program for Agricultural Biotechnology, National Science Council (NSC) in Taiwan (No. NSC95-2313-B-005-015) to JWH. $\mathrm{HCH}$ is a Emeritus Principal Research Scientist of Agriculture and Agri-Food Canada, who was a Visiting Chair Professor at Taiwan Agricultural Research Institute (2008-2013) supported by a fellowship from NSC.

\section{References}

1. Dave B, Sales MC, Walia M (1987) Resistance of different strains of Penicillium digitatum to imazalil treatment in California citrus packinghouses. Pro Florida State Hort Sci Soc 102: 178-179.

2. Brown GE (1989) Baseline sensitivity of Florida isolates of Penicillium digitatum to imazalil. Plant Dis 73: 773-774.

3. Eckert JW (1988) Dynamics of benzimidazole resistant Penicillium in the development of postharvest decays of citrus and pome fruit. Fungicide resistance in North America pp: 31-35.

4. Liu J, Sui Y, Wisniewski M, Droby S, Liu Y (2013) Utilization of antagonistic yeasts to manage postharvest fungal diseases of fruit. Intl J Food Microbiol 167: 153-160.

5. Appel DJ, Gees R, Coffey MD (1988) Biological control of the postharvest pathogen Penicillium digitatum on Eureka lemons. Phytopathology 12: 1595-1599.
6. Borras AD, Aguilar RV (1990) Biological control of Penicillium digitatum by Trichoderma viride on postharvest citrus fruit. Intl J Food Microbiol 11: $179-184$.

7. Huang Y, Wild BL, Morris SC (1992) Postharvest biological control of Penicillium digitatum decay on citrus fruit by Bacillus pumilus. Annal Appl Biol 120: 367- 372.

8. Smilanick JL, Denis-Arrue R (1992) Control of green molds of lemons with Pseudomonas species. Plant Dis 76: 481-485.

9. Huang Y, Deverall BJ, Morris SC (1995) Postharvest control of green mold on oranges by a strain of Pseudomonas glathei and enhancement of its biocontrol by heat treatment. Postharvest Biol Technol 13: 129-137.

10. Arras G (1996) Mode of action of an isolate of Candida famata in biological control of Penicillium digitatum in orange fruit. Postharvest Biol Technol 8: 191-198.

11. Bull CT, Stack JP, Smilanick JL (1997) Pseudomonas syringae strains ESC-10 and ESC-11 survive in wounds on citrus and control green and blue molds of citrus. Biol Control 8: 81-88.

12. Bull AD, Wadsworth ML, Sorenson KN, Takemoto J, Austin R, et al. (1998) Syringomycin E produced by biological agents controls green mold on lemons. Biol Control 12: 89-95.

13. El-Neshawy SM, El-Sheikh MM (1998) Control of green mold on oranges by Candida oleophila and calcium treatments. Annal Agri Sci 3: 881-890.

14. Usall J, Smilanick J, Palou L, Denis-Arrue N, Teixidó N, et al. (2008) Preventive and curative activity of combined treatments of sodium carbonates and Pantoea agglomerans CAP-2 to control postharvest green mold of citrus fruit. Postharvest Biol Technol 50: 1-7.

15. Droby S, Wisniewski M, Macarisin D, Wilson C (2009) Twenty years of postharvest biocontrol research: Is it time for a new paradigm? Postharvest Biol Technol 52: 137-145.

16. Hadar Y, Harman GE, Taylor AG, Norton JM (1983) Effects of pregermination of pea and cucumber seeds and of seed treatment with Enterobacter cloacae on rots caused by Pythium spp. Phytopathology 73: 1322-1325.

17. Sneh B, Dupler M, Elad Y, Baker R (1984) Chlamydospore germination of Fusarium oxysporum f. sp. cucumerinum as affected by fluorescent and lytic bacteria from a Fusarium-suppressive soil. Phytopathology 74: 1115-1124.

18. Wilson CL, Franklin JD, Pusey PL (1987) Biological control of Rhizopus soft rot of peach with Enterobacter cloacae. Phytopathology 77: 303-305.

19. Howell CR, Beier RC, Stipanovic RD (1988) Production of ammonia by Enterobacter cloacae and its possible role in the biological control of Pythium preemergence damping-off by the bacterium. Phytopathology 78: 1075-1078.

20. Nelson EB (1988) Biological control of Pythium seed rot and preemergence damping-off of cotton with Enterobacter cloacae and Erwinia herbicola applied as seed treatment. Plant Dis 72: 140-142.

21. Wisniewski M, Wilson C, Hershberger W (1989) Characterization of inhibition of Rhizopus stolonifer germination and growth by Enterobacter cloacae. Can J Bot 67: 2317-2323.

22. Nelson EB, Craft CM (1991) Introduction and establishment of strains of Enterobacter cloacae in golf course turf for the biological control of dollar spot. Plant Dis 75: 510-514.

23. Watanabe K, Abe K, Sato M (2000) Biological control of an insect pest by gut-colonizing Enterobacter cloacae transformed with ice nucleation gene. J Appl Microbiol 88: 90-97.

24. Loper JE, Ishimaru CA, Carnegie SR, Vanavichit A (1993) Cloning and characterization of aerobactin biosynthesis genes of the biological control agent Enterobacter cloacae. Appl Environ Microbiol 59: 4189-4197.

25. Dijk KV, Nelson EB (2000) Fatty acid competition as a mechanism by which Enterobacter cloacae suppresses Pythium ultimum sporangium germination and damping-off. Appl Environ Microbiol 66: 5340-5347.

26. Arrebola E, Sivakumar D, Korsten L (2010) Effect of volatile compounds produced by Bacillus strains on postharvest decay in citrus. Biol Control 53: $122-128$. 
Citation: Chen PS, Peng YH, Chung WC, Chung KR, Huang HC, et al. (2016) Inhibition of Penicillium digitatum and Citrus Green Mold by Volatile Compounds Produced by Enterobacter cloacae. J Plant Pathol Microbiol 7: 339. doi:10.4172/2157-7471.1000339

Page 8 of 8

27. Di Francesco A, Ugolini L, Lazzeri L, Mari M (2015) Production of volatile organic compounds by Aureobasidium pullulans as a potential mechanism of action against postharvest fruit pathogens. Biol Control 81: 8-14.

28. Ezra D, Strobel GA (2003) Effect of substance on the bioactivity of volatile antimicrobials produced by Muscodor albus. Plant Sci 165: 1229-1238.

29. Li Q, Ning P, Zheng L, Huang J, Li G, et al. (2012) Effects of volatile substances of Streptomyces globisporus JK-1 on control of Botrytis cinerea on tomato fruit. Biol Control 61: 113-120.

30. Mercier J, Smilanick JL (2005) Control of green mold and sour rot of stored lemon by biofumigation with Muscodor albus. Biol Control 32: 401-407.

31. Morath SU, Hung R, Bennett JW (2012) Fungal volatile organic compounds: A review with emphasis on their biotechnological potential. Fungal Biol Rev 26: 73-83.

32. Strobel GA (2006) Muscodor albus and its biological promise. J Indian Microbiol Biotechnol 33: 514-522.

33. Wan M, Li G, Zhang J, Jiang D, Huang HC (2008) Effect of volatile substances of Streptomyces platensis F-1 on control of plant fungal diseases. Biol Control 46: 552-559.

34. Sharma RR, Singh D, Singh R (2009) Biological control of postharvest diseases of fruits and vegetables by microbial antagonists: A review. Biol Control 50: 205-221.

35. Lee MH, Pan SM, Wu TW, Chen BS, Wang LY, et al. (2011) Mutations of $\beta$-tubulin codon 198 or 200 indicate thiabendazole resistance among isolates of Penicillium digitatum collected from citrus in Taiwan. Intl J Food Microbiol 150: 157-163.

36. Pitt JI (1979) The genus Penicillium and its teleomorphic states Eupenicillium and Talaromyces. Academic Press London p: 634.

37. White TJ, Bruns T, Lee S, Taylor JW (1990) Amplification and direct sequencing of fungal ribosomal RNA genes for phylogenetics. PCR Protocols: A Guide to Methods and Applications USA 18: 315-322.

38. Fukui Y, Sawabe T (2007) Improved one-step colony PCR detection of Vibrio harveyi. Microbe Environ 22: 1-10.

39. Mollet C, Drancourt M, Raoult D (1997) rpoB sequence analysis as a novel basis for bacterial identification. Mol Microbiol 26: 1005-1011.

40. Stinson M, Ezra D, Hess WM, Sears J, Strobel G (2003) An endophytic Gliocladium sp. of Eucryphia cordifolia producing selective volatile antimicrobial compounds. Plant Sci 165: 913-922.

41. Kai M, Effmert U, Berg G, Piechulla B (2007) Volatiles of bacteria; antagonists inhibit mycelial growth of the plant pathogen Rhizoctonia solani. Arch Microbiol 187: 351-360.
42. Gabler FM, Fassel R, Mercier J, Smilanick JL (2006) Influence of temperature, inoculation interval, and dosage on biofumigation with Muscodor albus to control postharvest gray mold on grapes. Plant Dis 90: 1019-1025.

43. Schotsmans WC, Braun G, DeLong JM, Prange RK (2008) Temperature and controlled atmosphere effects on efficacy of Muscodor albus as a biofumigant. Biol Control 44: 101-110.

44. Bevilacqua A, Cannarsi M, Gallo M, Sinigaglia M, Corbo MR (2010) Characterization of implications of Enterobacter cloacae strains, isolated from Italian table olives "Bella DiCerignola." Food Microbiol Safe 75: M53-M60.

45. Ming DW, Allen ER (2001) Use of natural zeolites in agronomy, horticulture and environmental soil remediation. Rev Mineral Geochem 45: 619-654.

46. Etschmann MM, Bluemke W, Sell D, Schrader J (2002) Biotechnological production of 2-phenylethanol. Appl Microbiol Biotechnol 59: 1-8.

47. Ezra D, Hess WM, Strobel GA (2004) New endophytic isolates of Muscodor albus, a volatile-antibiotic-producing fungus. Microbiology 150: 4023-4031.

48. Strobel GA, Kluck K, Hess WM, Sears J, Ezra D, et al. (2007) Muscodor albus E-6, and endophyte of Gauzuma ulmifolia, making volatile antibiotics: isolation, characterization and experimental establishment in the host plant. Microbiology 153: 2613-2620.

49. Lester G (1965) Inhibition of growth, synthesis, and permeability in Neurospora crassa by phenethyl alcohol. J Bacteriol 90: 29-37.

50. Lingappa BT, Lingappa Y, Turian G (1970) Phenethyl alcohol induced germination of ascospores of Neurospora. Archiv Mikrobiol 72: 97-105.

51. Ingram LO, Buttke TM (1984) Effects of alcohols on microorganisms. Adv Microbial Physiol 25: 253-300.

52. Lucchini JJ, Bonnaveiro N, Cremieux A, le Goffic F (1993) Mechanism of bactericidal action of pheylethyl alcohol in Escherichia coli. Curr Microbiol 27: 295-300

53. Hogan DA (2006) Quorum sensing: alcohols in a social situation. Curr Biol 12: R457-R458.

54. Bringmann G, Kühn R (1980) Comparison of the toxicity thresholds of water pollutants to bacteria, algae, and protozoa in the cell multiplication inhibition test. Water Res 14: 231-241.

55. Strobel GA, Spang S, Kluck K, Hess WM, Sears J, et al. (2008) Synergism among volatile organic compounds resulting in increased antibiosis in Oidium sp. FEMS Microbiol Lett 283: 140-145. 